\title{
Consumo, Digestibilidade e Balanço de Nitrogênio em Novilhos Alimentados com Cama de Frango e Suplemento à Base de Microbiota Ruminal Liofilizada ${ }^{1}$
}

\author{
Ronaldo Lopes Oliveira², José Carlos Pereira ${ }^{3}$, Paulo Roberto de \\ Carvalho e Silva ${ }^{2}$, Maria Ignez Leão ${ }^{4}$
}

\begin{abstract}
RESUMO - Este experimento foi realizado para avaliar o efeito de dois níveis de cama de frango (15,0 e 30,0\%), associada ou não a um suplemento à base de microbiota ruminal liofilizada de bovinos adultos ( 0 e $10 \mathrm{~g} / \mathrm{animal} \bullet$ dia $)$, na alimentação de novilhos Holandês/ Zebu. Quatro novilhos fistulados no rúmen e abomaso foram distribuídos em um quadrado latino 4 x 4 em arranjo fatorial e alimentados individualmente à vontade. O consumo e as digestibilidades totais e parciais dos nutrientes foram avaliados. Não houve efeito do nível de cama de frango sobre o consumo e os coeficientes de digestibilidade da matéria seca (MS), matéria orgânica (MO) e fibra em detergente neutro (FDN). O aumento do nível de cama de frango na dieta elevou o coeficiente de digestibilidade intestinal e total da proteína bruta (PB), porém, quando se adicionou o suplemento à dieta com 15,0\% de cama de frango, a digestibilidade intestinal aumentou e àquela contendo 30,0\% diminuiu. Quando se adicionou o suplemento à dieta com 15,0\% de cama de frango, o coeficiente de digestibilidade total não sofreu efeito, mas diminuiu para a dieta com 30\%. A ingestão diária de $10 \mathrm{~g}$ do suplemento, por animal, não alterou o consumo e os coeficientes de digestibilidade da MS, MO e FDN.
\end{abstract}

Palavras-chave: balanço de nitrogênio, cama de frango, consumo, digestibilidade, microbiota

\section{Intake, Digestibility and Nitrogen Balance of Steers Fed Broiler Litter and Supplement Based on Lyophilized Ruminal Microbiota}

\begin{abstract}
This experiment was conducted to evaluate the effect of two levels of broiler litter (15.0 and 30.0\%), associated or not to a supplement based on bovine lyophilized ruminal microbiota ( 0 and $10 \mathrm{~g} /$ animal $\bullet$ day), in the Holstein Zebu steers feeding. Four steers with ruminal and abomasal fistulae were allotted to a $4 \times 4$ latin square in a factorial arrangement and individually fullfed. The intake and total and partial digestibilities were evaluated. There was no effect of broiler litter level on the intake and coefficients of digestibilities of dry matter (DM), organic matter (OM) and neutral detergent fiber (NDF). The increase of the level of broiler litter in the diet increased the total and intestinal crude protein (CP) digestibility coefficient, however, when the supplement was added to the diet containing $15.0 \%$ of broiler litter, the intestinal digestibility increased, and that of $30.0 \%$ decreased. When the supplement was added to the diet containing $15.0 \%$ broiler litter, the total digestibility coefficient did not show effect, but decreased for the diet with $30.0 \%$. The daily intake of $10 \mathrm{~g}$ of supplement per animal did not affect the intake and the coefficient of digestibilities of DM, OM and NDF.
\end{abstract}

Key Words: nitrogen balance, broiler litter, intake, digestibility, microbiota

\section{Introdução}

O perfil nutricional da cama de frango é definido pelo material utilizado como base (capim maduro, cepilho, maravalha, casca de arroz ou de café, sabugo de milho, entre outros) por restos de ração e pelos excrementos das aves.

Variações na composição química da cama de frango ocorrem em função da densidade populacional, do tempo de permanência das aves sobre o material, da natureza e quantidade do material de cobertura e de fatores como período de estocagem e manejo da cama de frango.
Algumas práticas de manejo, durante a limpeza do aviário, devem ser seguidas, como excluir materiais e objetos estranhos e eliminar de partículas de solo e partes ou mesmo carcaças inteiras. O conteúdo de matéria mineral, que é oriundo do alimento, das excretas, do material de cobertura e do solo, é uma medida importante de qualidade. Segundo BLAKE e DONALD (1991), a cama de frango com conteúdo de cinzas acima de $28 \%$ não deve ser fornecida a bovinos.

Do nitrogênio existente na cama de frango, 50 a $60 \%$ são de origem não-protéica e o ácido úrico representa cerca de $30 \%$ do $\mathrm{N}$ total

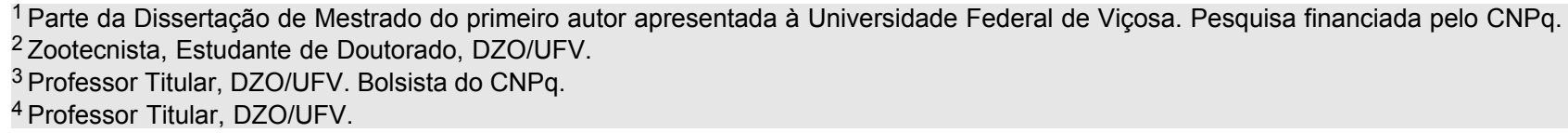


(BHATTACHARYA e FONTENOT, 1966). O ácido úrico é utilizado pelos microrganismos ruminais mais lentamente que a uréia, o que resulta em utilização mais eficiente do N pelos ruminantes (OLTJEN et al., 1968).

O aparecimento de doenças causadas por microrganismos cada vez mais resistentes aos antibióticos suscitou especulações a respeito do uso dos mesmos na alimentação animal e da possível ocorrência de resíduos na carne, no leite e nos ovos. Com isso, os antibióticos deixaram de ser utilizados na alimentação animal e as pesquisas então se voltaram para os probióticos, cujo objetivo principal é o aumento da microbiota desejável, ruminal ou intestinal, de modo que esta suplante os microrganismos patogênicos por competição.

Em ruminantes, os probióticos têm sido utilizados principalmente para bezerros. Esta medida é tomada com o intuito de diminuir a incidência de diarréias e conseqüente maior digestão e absorção dos nutrientes (GONÇALVES et al., 1997). A inoculação de microbiota no rúmen de bovinos vem sendo utilizada há muito tempo com sucesso. HUNGATE (1966) cita vários trabalhos em que foram inoculados microrganismos de bovinos adultos em bezerros. Entretanto, estudos com animais desaleitados, em crescimento, são escassos na literatura. Esse autor ainda comenta que a liofilização é uma forma muito comum de manter o inócuo, por facilitar sua administração a campo, porém há alguma perda de células microbianas no processo.

Por meio deste estudo, objetivou-se avaliar o efeito de diferentes níveis de cama de frango, associada ou não a um suplemento à base de microbiota ruminal liofilizada de bovinos adultos, sobre o consumo e as digestibilidades total e parcial da MS, MO, PB e FDN e sobre o balanço de nitrogênio em novilhos holandês/zebu.

\section{Material e Métodos}

O experimento foi conduzido no Departamento de Zootecnia da Universidade Federal de Viçosa, em Minas Gerais, no período de setembro a dezembro de 1996.

Foram utilizados quatro novilhos, predominantemente da raça holandesa, com idade aproximada de 1,5 anos e peso vivo médio de $307 \mathrm{~kg}$, fistulados no rúmen e abomaso conforme técnicas descritas por LEÃO et al. (1978) e LEÃO e COELHO DA SILVA (1980). Estes animais foram distribuídos aleatoriamente em baias individuais cobertas, contendo comedouros individuais, bebedouros automáticos tipo concha e piso cimentado, mantidos em boas condi- ções de higiene e, no período pré-experimental, foram vermifugados e vacinados contra febre aftosa.

A pesagem dos animais foi efetuada no início e final do experimento e no primeiro dia de cada período experimental. Estes dados foram utilizados para os cálculos do consumo em $\%$ do $\mathrm{PV}$ e $\mathrm{g} / \mathrm{kg}$ de $\mathrm{PV}^{0,75}$.

A duração do experimento foi de 90 dias, divididos em quatro períodos experimentais de 19 dias, sendo 10 dias destinados à adaptação às dietas e nove dias, às coletas de amostras. Houve um período préexperimental de 10 dias para que os animais se adaptassem ao sistema de estabulação.

Os tratamentos consistiram em dois níveis de cama de frango (15 e 30\% MS) associados a dois níveis de suplemento comercial à base de microbiota ruminal liofilizada (0 e $10 \mathrm{~g}$ /animal•dia). Para isso, foram utilizados quatro animais, dispostos em quadrado latino (quatro animais $\mathrm{x}$ quatro períodos $\mathrm{x}$ quatro tratamentos) e em esquema fatorial ( $2 \times 2$ - dois níveis de cama de frango $x$ dois níveis de suplemento). Não havendo interação, as médias eram contrastadas pelo teste F a 5\% de significância e em caso positivo, pelo teste Newman-Keuls (5\% de significância).

Os dados experimentais foram analisados utilizandose o programa SAEG - Sistema de Análises Estatísticas (UNIVERSIDADE FEDERAL DE VIÇOSA, 1995).

Os animais receberam feno do capim coastcross (Cynodon dactylon (L.) Pers.) como volumoso e os concentrados constituíram-se de farelo de soja e fubá de milho, além de suplemento mineral. Estes foram misturados de modo que as dietas apresentassem teores semelhantes de PB. A dieta foi calculada para taxa de ganho de peso estimado de 700 a 800 g/dia, de acordo com o NRC (1989).

O material base da cama de frango foi o capimelefante (Pennisetum purpureum Schum.) em estádio avançado de maturação, seco e picado. Armazenou-se a cama de frango por dois meses antes do experimento, sob lona plástica, em galpão coberto. Este armazenamento foi feito com o intuito de eliminar microrganismos potencialmente patogênicos, uma vez que esse material não sofreu nenhum tipo de processamento (FONTENOT e WEBB, 1975, McCASKEY e ANTHONY, 1979).

O suplemento à base de microbiota ruminal liofilizada foi oferecido em doses de $5 \mathrm{~g}$, duas vezes ao dia, misturado a uma porção de concentrado, antes de cada arraçoamento. $\mathrm{O}$ arraçomento não era feito enquanto os animais não consumissem todo o suplemento.

Nos primeiros 10 dias de cada período, o consumo foi determinado diariamente para ajustar as sobras ao 
redor de $10 \%$. A ingestão média nos seis dias seguintes à adaptação $\left(11^{\circ}\right.$ ao $16^{\circ}$ dia experimental $)$ foi considerada como o consumo voluntário de MS.

A composição químico-bromatológica dos ingredientes e das dietas constam da Tabela 1 e 2, respectivamente. Na Tabela 2 também estão descritas as proporções de cada ingrediente.

A duração do ensaio de fluxo da digesta, excreção fecal e digestibilidade foi de 16 dias, sendo que 10 dias foram de adaptação ao período experimental e seis dias para as coletas. Durante todos os dias do ensaio, foram introduzidos, pela cânula ruminal, $10 \mathrm{~g}$ do indicador (óxido crômico - $\mathrm{Cr}_{2} \mathrm{O}_{3}$ ) embrulhados em papel, sendo $5 \mathrm{~g}$ de manhã e $5 \mathrm{~g}$ à tarde. Nesse período foram coletadas amostras da dieta e das sobras, que formaram amostras compostas por animal e por período experimental, acondicionadas em sacos plásticos identificados e armazenados em congelador, $\mathrm{a}-10^{\circ} \mathrm{C}$, para posteriores análises. Durante os períodos de coleta, logo após o fornecimento do indicador, foram coletadas duas amostras diárias de fezes diretamente do reto, em quantidade aproximada de $200 \mathrm{~g}$. Estas amostras foram homogeneizadas manualmente e colocadas em pratos de alumínio, procedendo-se à pré-secagem em estufa de ventilação forçada a $60 \pm 5^{\circ} \mathrm{C}$, por 72 horas. Após, as amostras foram moídas em moinho tipo Willie, com peneira de $1 \mathrm{~mm}$, e armazenadas como amostras compostas por animal e período. Nestas amostras foram efetuadas as análises de cromo (Cr), MS, MO, PB e FDN para a determinação da digestibilidade total e do balanço de $\mathrm{N}$.

Durante os seis dias de fornecimento do indicador, procedeu-se à coleta de $500 \mathrm{~mL}$ de digesta abomasal a intervalos de 28 horas, totalizando seis amostragens, que foram conservadas em congelador a $-10^{\circ} \mathrm{C}$, para a determinação das digestibilidades parciais. O material coletado, após ser descongelado e seco em estufa, deu origem a amostras compostas por animal e período, no qual foram determinados os teores de $\mathrm{Cr}, \mathrm{MS}, \mathrm{MO}, \mathrm{PB}$ e FDN, análises estas relativas às digestibilidades parciais.

O cálculo do coeficiente de digestibilidade total (CDT), do coeficiente de digestibilidade ruminal(CDR), bem como do fluxo de MS abomasal (MAS), de cada nutriente, foi efetuado segundo descrito por OLIVEIRA (1998). O coeficiente de digestibilidade intestinal (CDI) foi calculado por diferença (100-CDR).

$O$ coeficiente de digestibilidade ruminal da $\mathrm{PB}$ (CDRPB) foi calculado em função do fluxo de PB microbiana, pela seguinte fórmula:

$\mathrm{CDRPB}=\frac{\mathrm{PB} \text { ingerida }-(\mathrm{PB} \text { total no abomaso }-\mathrm{PB} \text { microbiana no abomaso })}{\mathrm{PB} \text { ingerida }} \times 100$

O fluxo de MS microbiana para o abomaso foi calculado em função do fluxo de MS total, e o fluxo de PB microbiana, da seguinte maneira:

$$
\text { Fluxo } \mathrm{PB}_{\text {mic }}=\frac{\mathrm{N}_{\mathrm{RNA}} \text { no abomaso }}{\left(\mathrm{N}_{\mathrm{RNA}} / \mathrm{N}_{\text {total }} \text { no microrganismo }\right)} \times 6,25
$$

No $19^{\circ}$ dia de cada período experimental, os coletores de urina foram colocados nos animais e, após, procedeu-se à coleta total da mesma durante 24 horas, que foi armazenada em recipientes contendo $100 \mathrm{~mL}$ de $\mathrm{H}_{2} \mathrm{SO}_{4}$. Após pesagem, foram retiradas alíquotas, que foram congeladas para posteriores análises de N-total.

As análises laboratoriais dos teores de MS, matéria orgânica (MO) e PB foram realizadas conforme metodologias descritas por SILVA (1990), e as de fibra em detergente neutro (FDN), segundo GOERING e VAN SOEST (1970).

O conteúdo de $\mathrm{Cr}$ nas amostras de digesta e fezes foi determinado por espectrofotometria de absorção atômica, conforme metodologia proposta por WILLIAMS et al. (1962).

Tabela 1 - Composição química dos ingredientes (\% MS)

\begin{tabular}{|c|c|c|c|c|}
\hline Componente & $\mathrm{MS}(\%)$ & $\mathrm{MO}$ & PB & FDN \\
\hline Component & $D M$ & $O M$ & $C P$ & $N D F$ \\
\hline Feno de coast-cross & 87,64 & 92,41 & 5,95 & 83,26 \\
\hline Coast-cross hay & & & & \\
\hline $\begin{array}{l}\text { Cama de frango } \\
\text { Broiler litter }\end{array}$ & 73,49 & 83,23 & 17,83 & 59,89 \\
\hline $\begin{array}{l}\text { Concentrado } 1 \\
\text { Concentrate }\end{array}$ & 82,17 & 96,86 & 17,33 & 25,74 \\
\hline $\begin{array}{l}\text { Concentrado } 2 \\
\text { Concentrate }\end{array}$ & 82,52 & 97,41 & 11,84 & 27,54 \\
\hline
\end{tabular}


Rev. bras. zootec.

Tabela 3 - Consumo de matéria seca (MS), matéria orgânica, proteína bruta e fibra em detergente neutro Table 3 - Intake of dry matter (DM), organic matter, crude protein and neutral detergent fiber

\begin{tabular}{|c|c|c|c|c|}
\hline \multirow[t]{3}{*}{ Item } & \multicolumn{4}{|c|}{$\begin{array}{c}\text { Tratamento } \\
\text { Treatment }\end{array}$} \\
\hline & \multicolumn{2}{|c|}{$\begin{array}{c}\text { Nível de cama de frango (\% MS) } \\
\text { Broiler litter level }(\% D M)\end{array}$} & \multicolumn{2}{|c|}{$\begin{array}{c}\text { Nível de suplemento }(\mathrm{g} / \mathrm{anim} \bullet \mathrm{d}) \\
\text { Supplement level }\end{array}$} \\
\hline & 15 & 30 & 0 & 10 \\
\hline & \multicolumn{4}{|c|}{$\begin{array}{l}\text { Matéria seca } \\
\text { Dry matter }\end{array}$} \\
\hline$\% \mathrm{PV}$ & 1,99 & 1,82 & 1,98 & 1,83 \\
\hline \multirow[t]{2}{*}{$\begin{array}{l}\% L W \\
\mathrm{~g} / \mathrm{kg} \mathrm{PV} \mathrm{PV}^{0,75} \\
\mathrm{~g} / \mathrm{kg} L W^{0.75}\end{array}$} & 83,45 & 76,11 & 82,81 & 76,76 \\
\hline & \multicolumn{4}{|c|}{$\begin{array}{l}\text { Matéria orgânica } \\
\text { Organic matter }\end{array}$} \\
\hline $\begin{array}{l}\mathrm{kg} / \mathrm{dia} \\
\mathrm{kg} / \text { day }\end{array}$ & 6,03 & 5,32 & 6,00 & 5,35 \\
\hline $\begin{array}{l}\% \mathrm{PV} \\
\% L W\end{array}$ & 1,96 & 1,73 & 1,94 & 1,74 \\
\hline \multirow[t]{2}{*}{$\begin{array}{l}\mathrm{g} / \mathrm{kg} \mathrm{PV} \mathrm{PV}^{0,75} \\
\mathrm{~g} / \mathrm{kg} L W^{0.75}\end{array}$} & 81,94 & 72,31 & 81,36 & 72,89 \\
\hline & \multicolumn{4}{|c|}{$\begin{array}{l}\text { Proteína bruta } \\
\text { Crude protein }\end{array}$} \\
\hline $\mathrm{kg} / \mathrm{dia}$ & 0,85 & 0,71 & 0,80 & 0,75 \\
\hline $\begin{array}{l}\mathrm{kg} / \text { day } \\
\% \mathrm{PV} \\
\% L W\end{array}$ & 0,27 & 0,23 & 0,26 & 0,25 \\
\hline \multirow[t]{2}{*}{$\begin{array}{l}\mathrm{g} / \mathrm{kg} \mathrm{PV} \mathrm{PV}^{0,75} \\
\mathrm{~g} / \mathrm{kg} L W^{0.75}\end{array}$} & 11,51 & 9,64 & 10,87 & 10,28 \\
\hline & \multicolumn{4}{|c|}{$\begin{array}{l}\text { Fibra em detergente neutro } \\
\text { Neutral detergent fiber }\end{array}$} \\
\hline $\begin{array}{l}\mathrm{kg} / \mathrm{dia} \\
\mathrm{kg} / \text { day }\end{array}$ & 3,25 & 2,82 & 2,96 & 3,12 \\
\hline $\begin{array}{l}\% \mathrm{PV} \\
\% L W\end{array}$ & 1,07 & 0,93 & 0,97 & 1,02 \\
\hline $\begin{array}{l}\mathrm{g} / \mathrm{kg} \mathrm{PV} V^{0,75} \\
\mathrm{~g} / \mathrm{kg} L W^{0.75}\end{array}$ & 44,58 & 38,70 & 40,52 & 42,76 \\
\hline
\end{tabular}

significativo sobre o consumo. Apesar disso, quando o suplemento foi fornecido, os animais não atingiram os consumos de MS e PB preconizados pelo NRC (1989).

Os coeficientes de digestibilidade aparente total (CDT), ruminal (CDR) e intestinal (CDI) da MS, MO, PB e FDN estão descritos na Tabela 4.

Com exceção do CDI e CDT da $\mathrm{PB}(\mathrm{P}<0,05)$, não se verificou interação significativa entre os níveis de cama de frango e os níveis de suplemento. Não houve efeito da cama de frango e/ou do suplemento sobre o CDR da MS, MO, PB e FDN e os CDI e CDT da MS, MO e FDN.

Entretanto, quando o teor de cama de frango foi elevado de 15 para $30 \%$ na dieta de vacas, BROSH et al. (1993) verificaram que o CDT da MS subiu de 47,2 para $56,8 \%$ e o da $\mathrm{MO}$, de 51,7 para $60,6 \%$.
Provavelmente, o nutriente responsável por esse aumento no CDT da MS, quando se elevou o nível de cama de frango na dieta, foi a $\mathrm{PB}$, devido à sua alta degradação ruminal.

BROSH et al. (1993) também encontraram maior CDT da PB, quando o nível de cama de frango na dieta passou de $15(37,9 \%)$ para 30\% (47,6\%). Entretanto, HARMON et al. (1975) constataram que, apesar de o CDT da PB aumentar de 59,9 para 67\%, quando o nível de cama de frango passou de 15 para $30 \%$ na dieta de ovinos, o CDT da MS diminuiu de 65 para $63,4 \%$.

Os CDT observados neste trabalho estão dentro das variações encontradas na literatura para dietas com cama de frango. Estas variações vão de 47,2 a 
OLIVEIRA et al.

Tabela 4 - Coeficiente de digestibilidade aparente ruminal (CDR), intestinal (CDI) e total (CDT) da matéria seca (MS), matéria orgânica, proteína bruta e fibra em detergente neutro

Table 4 - Ruminal (RDC), intestinal (IDC) and total (TDC) Ccefficient apparent digestibility of dry matter (DM), organic matter, crude protein and neutral detergent fiber

\begin{tabular}{|c|c|c|c|c|}
\hline \multirow[t]{3}{*}{ Item } & \multicolumn{4}{|c|}{$\begin{array}{c}\text { Tratamento } \\
\text { Treatment }\end{array}$} \\
\hline & \multicolumn{2}{|c|}{$\begin{array}{c}\text { Nível de cama de frango }(\% \mathrm{MS}) \\
\text { Broiler litter level }(\% \text { DM) }\end{array}$} & \multicolumn{2}{|c|}{$\begin{array}{l}\text { Nível de suplemento }(\mathrm{g} / \mathrm{anim} \bullet \mathrm{d}) \\
\text { Supplement level }\end{array}$} \\
\hline & 15 & 30 & 0 & 10 \\
\hline & \multicolumn{4}{|c|}{$\begin{array}{l}\text { Matéria seca } \\
\text { Dry matter }\end{array}$} \\
\hline $\begin{array}{l}\mathrm{CDR}^{1} \\
R D C\end{array}$ & 55,46 & 52,17 & 51,14 & 56,48 \\
\hline $\begin{array}{l}\mathrm{CDI}^{1} \\
I D C\end{array}$ & 44,54 & 47,83 & 48,86 & 43,52 \\
\hline \multirow{2}{*}{$\begin{array}{l}I D C \\
\text { CDT } \\
T D C\end{array}$} & 50,52 & 52,18 & 51,29 & 51,41 \\
\hline & \multicolumn{4}{|c|}{$\begin{array}{l}\text { Matéria orgânica } \\
\text { Organic matter }\end{array}$} \\
\hline $\begin{array}{l}\mathrm{CDR}^{1} \\
R D C\end{array}$ & 65,34 & 68,80 & 68,50 & 65,65 \\
\hline $\begin{array}{l}\mathrm{CDI}^{1} \\
I D C\end{array}$ & 34,66 & 31,20 & 31,50 & 34,35 \\
\hline \multicolumn{5}{|l|}{$T D C$} \\
\hline \multirow{3}{*}{$\begin{array}{l}\mathrm{CDR}^{2 *} \\
R D C\end{array}$} & \multicolumn{4}{|c|}{$\begin{array}{l}\text { Proteína bruta } \\
\text { Crude protein }\end{array}$} \\
\hline & 50,74 & 59,65 & 55,90 & 54,49 \\
\hline & \multicolumn{4}{|c|}{$\begin{array}{c}\text { Fibra em detergente neutro } \\
\text { Neutral detergent fiber }\end{array}$} \\
\hline $\begin{array}{l}\mathrm{CDR}^{1} \\
R D C\end{array}$ & 43,96 & 45,52 & 44,94 & 44,54 \\
\hline $\begin{array}{l}\mathrm{CDI}^{1} \\
I D C\end{array}$ & 56,04 & 54,48 & 55,06 & 55,46 \\
\hline $\begin{array}{l}\text { CDT } \\
T D C\end{array}$ & 45,03 & 44,82 & 46,80 & 43,05 \\
\hline
\end{tabular}

$79,1 \%$ para MS; 51,7 a $62,3 \%$ para MO; e 37,9 a $74, \%$ para PB (BHATTACHARYA e FONTENOT, 1965; BHATTACHARYA e FONTENOT, 1966; FONTENOT et al., 1966; HARMON et al., 1974; HARMON etal., 1975; CASWELL etal., 1977; ARIELI et al., 1991; BROSH et al., 1993; e PATIL et al., 1993).

Devido à dinâmica da proteína no rúmen, os valores do CDRPB calculados com o óxido crômico apresentaram-se negativos. Então, para sanar este problema, os cálculos foram feitos em função do fluxo de MS microbiana para o abomaso, que foi estimado utilizando-se como indicador as bases purínicas. Assim, determinou-se a porcentagem real da PB da dieta, que foi digerida no rúmen. Os dados são mostrados em função do total de PB que chega em cada local digestão.
O CDT da FDN encontrado neste trabalho (45,03\%), para o nível de $15 \%$ de cama de frango na dieta, está acima do descrito por PATIL et al. (1993). Esses autores, trabalhando com novilhas holandesas alimentadas com feno de capim bermuda (Cynodon dactylon) suplementado com 8 e $15 \%$ de cama de frango, encontraram CDT da FDN de 57,6 e 56,1\%, respectivamente. Esses autores também estudaram o efeito da cama de frango sobre a digestibilidade da FDN, mas utilizaram feno de bromegrass (Bromus $s p$.) e verificaram que, à medida que a cama de frango substituía o milho, a digestibilidade da FDN do feno era melhorada. Isto ocorreu, provavelmente, devido à liberação de amônia proporcionada pela cama de frango, favorecendo a atividade dos microrganismos fibrolíticos, visto que utilizam apenas esse 
composto como fonte de N.

$\mathrm{Na}$ Tabela 5 estão desdobrados os efeitos interativos da cama de frango e do suplemento. As razões pelas quais a elevação no nível de cama de frango proporcionou aumentos $(\mathrm{P}<0,05)$ no $\mathrm{CDIPB}$ são desconhecidas.

$\mathrm{O}$ efeito de interação mostrou que a adição de suplemento às dietas com $15 \%$ de cama de frango proporcionou aumento $(\mathrm{P}<0,05)$ do CDIPB (de 44,27 para $46,31 \%$ ), enquanto, para $30 \%$, o suplemento promoveu queda $(\mathrm{P}<0,05)$ deste coeficiente (de 56,4 para $50,56 \%$ ).

$\mathrm{O}$ efeito do suplemento encontrado nos intestinos não é bem explicado, já que, por ser à base de microbiota de rúmen, a ação esperada seria em tal compartimento.

O suplemento exerceu efeito $(\mathrm{P}<0,05)$ sobre o CDTPB apenas para o tratamento cuja dieta continha $30 \%$ de cama de frango, promovendo diminuição deste coeficiente de 55,05 para $48,05 \%$.

$O$ aumento na inclusão de cama de frango na dieta elevou ( $(\mathrm{P}<0,05)$ o CDTPB de 40,84 para $55,55 \%$ (sem suplemento) e de 41,54 para $48,05 \%$ (com suplemento), o que provavelmente está relacionado à alta digestibilidade ruminal da ração, que, por sua vez, foi influenciada pela degradação da proteína da cama de frango. A PB da cama de frango tem elevada fração prontamente solúvel e degradável (VALADARES FILHO et al., 1990), e como esta substitui o farelo de soja, é de se esperar que o resíduo nitrogenado indigestível seja menor.

$\mathrm{O}$ balanço de nitrogênio diário, expresso em $\mathrm{g} / \mathrm{dia}$, em função do nível de cama de frango e do suplemento, consta da Tabela 6. Este parâmetro foi influenciado $(\mathrm{P}<0,05)$ pelo nível de cama de frango na dieta. Nas dietas com $30 \%$ de cama de frango, verificaram-se valores negativos para este parâmetro, que provavelmente está relacionado ao menor consumo de PB para este tratamento. Freqüentemente verificava-se seleção de alimento no cocho, com sobra de maior proporção de cama de frango, componente mais rico em $\mathrm{N}$ da dieta.

BHATTACHARYA e FONTENOT (1965) também observaram queda, de 2,14 para $0,71 \mathrm{~g} / \mathrm{d}$ de $\mathrm{N}$ retido, quando a proteína da cama de frango substituiu de 0 a $100 \%$ a do farelo de soja. Estes resultados vão de encontro aos descritos por HARMON et al. (1975), que, em pesquisa com carneiros que recebiam 15 ou $30 \%$ de cama de frango na dieta, verificaram maior retenção no nível mais alto de inclusão (4,47 contra 5,18 g/dia).
Tabela 5 - Coeficiente de digestibilidade intestinal e total da proteína bruta (PB)

Table 5 - Coefficient of intestinal and total digestibility of crude protein $(C P)$

Nível de cama de frango Nível de suplemento

(\% MS)

Broiler litter level (\% DM) (g/animød)

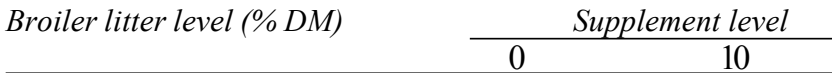

Coeficiente de digestibilidade intestinal da $\mathrm{PB}^{1}$ Coefficient of intestinal digestibility of $\mathrm{CP}^{1}$

15

30 $44,27 \mathrm{~B}^{\mathrm{b}} \quad 46,31^{\mathrm{Ba}}$ $56,4 \mathrm{~A}^{\mathrm{a}} \quad 50,56^{\mathrm{Ab}}$ Coeficiente de digestibilidade total da $\mathrm{PB}^{2}$ Coefficient of total digestibility of $\mathrm{CP}^{2}$

$15 \quad 40,84^{\mathrm{Ba}} \quad 41,54^{\mathrm{Ba}}$

$30 \quad 55,05^{\mathrm{Aa}} \quad 48,05^{\mathrm{Ab}}$

Médias, na linha/coluna, seguidas de letras maiúsculas e minúsculas iguais não diferem $(P<0,05)$ pelo teste Newman-Keuls.

$1 \%$ da quantidade no local.

$2 \%$ do total digestível.

Means, within a row/column, followed by different capital and small letters do not differ $(P<.05)$ by Newman-Keuls test.

$1 \%$ of the amount on the place.

$2 \%$ of total digestible.

Tabela 6 - Balanço de nitrogênio (BN)

Table 6 - Nitrogen balance (NB)

Item

Tratamento

Treatment

de frango $(\% \mathrm{MS}) \quad$ (g/animød)

Broiler litter level $(\% D M) \quad$ Supplement level

\begin{tabular}{|c|c|c|c|c|}
\hline & \multicolumn{2}{|l|}{$\sigma_{1}$} & \multicolumn{2}{|c|}{ Supplement level } \\
\hline & 15 & 30 & 0 & 10 \\
\hline$\overline{\mathrm{BN}}$ (g/dia) & $19,16^{\mathrm{a}}$ & $-17,39^{b}$ & 1,80 & $-0,04$ \\
\hline
\end{tabular}

$N B$ (g/day)

Médias, na coluna, seguidas de letras iguais não diferem $(P<0,05)$ pelo teste Newman-Keuls.

Means, within a column, followed by different letters do not differ $(P<.05)$ by Newman-Keuls test.

\section{Conclusões}

O nível de cama de frango e o suplemento à base de microbiota ruminal não influenciaram os consumos e os coeficientes de digestibilidade da MS, MO e FDN.

É conveniente, concomitante a ensaios de digestibilidade ruminal da $\mathrm{PB}$, determinar o fluxo de proteína microbiana para o abomaso para as devidas correções de valores negativos, já que o óxido crômico não se mostrou eficiente para esta estimativa.

Níveis mais elevados de cama de frango na dieta produziram aumento no coeficiente de digestibilidade 
intestinal e total da PB. Quando se adicionou o suplemento à base de microbiota ruminal à dieta com $15 \%$ de cama de frango, a digestibilidade intestinal aumentou e a total não sofreu efeito, porém, à dieta com $30 \%$ de cama de frango, ambos os coeficientes diminuíram.

Mais estudos devem ser feitos para avaliar os efeitos de níveis maiores do suplemento sobre a cinética da digestão em ruminantes.

\section{Referências Bibliográficas}

ARIELI, A., PECHT, Y., ZAMWELL, S. et al. 1991. Nutritional adaptation of heifers to diets containing poultry litter. Livestock Prod. Sci., 28:53-63.

BHATTACHARYA, A.N., FONTENOT, J.P. 1966. Protein and energy value of peanut hull and wood shaving poultry litters. J. Anim. Sci., 25:367-371.

BHATTACHARYA, A.N., FONTENOT, J.P. 1965. Utilization of different levels of poultry litter nitrogen by sheep. J. Anim. Sci., 24:1174-1178.

BLAKE, J.P., DONALD, J.O. 1991. Poultry by-product management handbook. Alabama Cooperative Extension Service, Alburn University, AL.

BROSH, A., HOLZER, Z., AHARONI, Y. et al. 1993. Intake, rumen volume, retention time and digestibility of diets based on poultry litter and wheat straw in beef cows before and after calving. J. Agric. Sci., 121:103-109.

CASWELL, L.F., WEBB JR., K.E., FONTENOT, J.P. 1977. Fermentation, nitrogen utilization, digestibility and palatability of broiler litter ensiled with high moisture corn grain. J. Anim. Sci., 44:803-813.

CROSS, D.L., SKELLEY, G.C., TOMPSON, C.S. et al. 1978. Efficacy of broiler litter silage for beef steers. J. Anim. Sci., 47:544-551.

FONTENOT, J.P., BHATTACHARYA, A.N., DRAKE, C.L. et al. Value of broiler litter as feed for ruminants. In: NATIONAL SYMPOSIUM ON MANAGEMENT OF FARM ANIMAL WASTES, St. Joseph, 1966. Proceedings... ASAE Publ.: St. Joseph, p.105-108, 1966.

FONTENOT, J.P., WEBB JR., K.E. 1975. Health aspects of recycling animal wastes by feeding. J. Anim. Sci., 40:1267-1275.

GOERING, H. K., VAN SOEST, J. P. 1970. Foragefiber analysis (apparatus reagents, procedure, and some applications). Agric. Handbook, ARS, USDA. Washington, DC, 379p.

GONÇALVES, G.D., SANTOS, G.T., RIGOLON, L.P. et al. Efeito da adição de probióticos na dieta, sobre o estado sanitário e desempenho de bezerros da raça holandesa. In: REUNIÃO ANUAL DA SOCIEDADE BRASILEIRA DE ZOOTECNIA, 34, Juiz de Fora, MG, 1997. Anais... Juiz de Fora: SBZ, p.218-220, 1997.

HARMON, B.W., FONTENOT, J.P., WEBB JR., K.E. 1974. Effect of processing method of broiler litter on nitrogen utilization by lambs. J. Anim. Sci., 39(942):946.
HARMON, B.W., FONTENOT, J.P., WEBB JR., K.E. 1975. Ensiled broiler litter and corn forage. I. Digestibility, nitrogen utilization and palatability by sheep. J. Anim. Sci., 40:156-160.

HUNGATE, R.E. 1966. The rumen and its microbes. London: Academic Press. 533p.

LEÃO, M.I., COELHO DA SILVA, J.F. Técnica de fistulação de abomaso em bezerros. In: REUNIÃO ANUAL DA SOCIEDADE BRASILEIRA DE ZOOTECNIA, 17, Fortaleza, CE, 1980. Anais... Fortaleza: SBZ, 1980. p.37.

LEÃO, M.I., COELHO DA SILVA, J.F., CARNEIRO, L.N.D.M. 1978. Implantação de fístula ruminal e cânula duodenal reentrante em carneiros para estudos de digestão. $R$. Ceres, 25:4254.

McCASKEY, T.A., ANTHONY, W.B. 1979. Human and animal health aspects of feeding livestock excreta. J. Anim. Sci., 48:163-171.

NATIONAL RESEARCH COUNCIL - NRC. 1989. Nutrient requirements of dairy cattle. $157 \mathrm{p}$.

OLIVEIRA, R.L. Cinética digestiva em novilhos submetidos a dietas com diferentes niveis de cama de frango e de suplemento à base de microbiota ruminal. Viçosa, MG:UFV, 1998, 69p. Dissertação (Mestrado em Zootecnia) - Universidade Federal de Viçosa, 1998.

OLTJEN, R.R., SLYTER, L.L., KOZAK, A.S. et al. 1968. Evaluation of urea, biuret, urea phosphate and uric acid as NPN sources for cattle. J. Nut., 94:193-202.

PATIL, A.R., GOETSHC, A.L., GALLOWAY, D.L et al. 1993. Intake and digestion by Holstein steers calves consuming grass hay supplemented with broiler litter. Anim. Feed Sci. Technol., 44:251-263.

SILVA, D. J. 1990. Análise de alimentos (Métodos químicos e biológicos). Viçosa. Imprensa Universitária. 166p.

UNIVERSIDADE FEDERAL DE VIÇOSA (UFV). S.A.E.G. (Sistema de Análises Estatísticas e Genéticas). Viçosa, MG, 1995. (Versão 7.0).

VALADARES FILHO, S.C., COELHO DA SILVA, J.F., LEÃO, M.I. et al. 1990b. Degradabilidade in situ da matéria seca e proteína bruta de vários alimentos em vacas em lactação. $R$. Soc. Bras. Zootec., 20:111-122.

WILLIAMS, C.H., DAVID, D.J., IISMAA, O. 1962. The determination of chromic oxide in faeces samples by atomic absorption spectrophotometry. J. Agric. Sci., 59:381-385.
Recebido em: 28/05/98

Aceito em: 25/01/99 